http://doi.org/10.35784/iapgos.2404

\title{
INVESTIGATION OF THE DEPENDENCE OF THE STRUCTURE OF SHIFT INDEXES VECTORS ON THE PROPERTIES OF RING CODES IN THE MOBILE NETWORKS OF THE INTERNET OF THINGS
}

\author{
Vladislav Kravchenko, Olena Hryshchenko, Viktoriia Skrypnik, Hanna Dudarieva \\ State University of Telecommunications, Kiev, Ukraine
}

\begin{abstract}
The essence of the concept of a family of several codes and its properties is considered. Typical structures of shear vectors for a family of several codes are analyzed. The regularity of determining the decimal values of the elements of the shift vectors and their dependence on the length of the code combinations and the number of single characters in the code combination is determined. The defined regularities allow algorithms to be developed to decode information with the use of the structure of the shift vectors.
\end{abstract}

Keywords: ring code, ring code family, shift indexes vector, code combination length

\section{BADANIE ZALEŻNOŚCI STRUKTURY WEKTORÓW INDEKSÓW PRZESUNIĘCIA OD WŁAŚCIWOŚCI KODÓW PIERŚCIENIOWYCH W MOBILNYCH SIECIACH INTERNETU RZECZY}

Streszczenie. Rozważono istotę pojęcia rodziny kodów pierścieniowych i jej właściwości. Przeanalizowano typowe struktury wektorów przesunięć dla rodziny kilku kodów. Określono prawidłowości wyznaczania wartości dziesiętnych elementów wektorów przesunięć i ich zależności od długości kombinacji kodowych oraz liczby pojedynczych znaków w kombinacji kodowej. Wyznaczone prawidłowości pozwalaja na opracowanie algorytmów dekodowania informacji z wykorzystaniem struktury wektorów przesunięcia.

Słowa kluczowe: kod pierścieniowy, rodzina kodów pierścieniowych, wektor offsetowy, długość kombinacji kodów

\section{Introduction}

According to [1-3], ring codes are built on the principle block cyclic code rows forming matrices that are interconnected by the condition of cyclicity. The ring code differs from the cyclic code in that the generating matrix of the ring code is always square and contains $\mathrm{N}$ columns and $\mathrm{N}$ rows, each row of which consists of $\mathrm{m}$ ones and $\mathrm{N}-\mathrm{m}$ zeros [1-3].

Ring codes are characterized by a vector of shear shift which is formed by adding the number of units obtained by bitwise implementation of one of the binary transformations XOR, OR, AND elements of the first line of the forming matrix of the ring code and the rest of its lines [3]. The shear vector shift is a group integral index of the ring code and the number of elements in the vector of the shear shift is always one less than the number of elements in the code combination of the ring code.

Any vector of shear shift characterizes a family of ring codes of a certain type.

\section{Properties of ring code families}

Each line of the generating matrix of the ring code is characterized by a delta factor - the distribution of zero and single symbols between the two extreme units, separated by the largest number for this initial vector of zero symbols. Ring codes that have a delta factor of a certain type create a family of ring codes. For example, Table 1 shows a family of ring codes depending on the type of delta factor

Table 1. Families of ring codes depending on the type of delta factor

\begin{tabular}{|c|c|c|}
\hline $\begin{array}{c}\text { Structure of code } \\
\text { combinations of the } \\
\text { family of ring codes of } \\
\text { type } 000111\end{array}$ & $\begin{array}{c}\text { Structure of code } \\
\text { combinations of the } \\
\text { family of ring codes of } \\
\text { type } 010101\end{array}$ & $\begin{array}{c}\text { Structure of the shear } \\
\text { vector }\end{array}$ \\
\hline 0000000001 & 0101 & 0000000001 \\
\hline 0000000011 & 010101 & 0000000101 \\
\hline 0000000111 & 01010101 & 0000001101 \\
\hline 0000001111 & 0101010101 & 0000001101 \\
\hline 0000011111 & 010101010101 & 0000011101 \\
\hline 0000111111 & 01010101010101 & 000011101 \\
\hline 0001111111 & 0101010101010101 & 0001111101 \\
\hline
\end{tabular}

The first column of Table 1 shows a family of ring codes of type 000111, single symbols in the delta factor that are placed in a row. The second column of the Table shows a family of ring codes of type 010101, single and zero symbols in the delta factor that alternate with each other. The third column of the Table shows a family of ring codes of type 001101, in the delta factor of which the ones are placed both in a row and alternating with zero symbols. Thus, within a family of codes, the ring structure combinations of the ones and zeros in the code combinations are identical. Code combinations differ only in the number of ones and zeros, without changing the structure of the combinations of the ones and zeros.

\section{Structure of vector of a shear shift of ring codes}

In order to analyze the structure of the vectors of the shift of the ring codes, the vectors of the shear shift for three types of families of ring codes are considered: type 000111, type 010101 and type 010011 . The study of the structure of the shear vectors of the above families allows us to note that within a certain family, the vectors of the shear shift have the same structure of alternation of decimal values of elements. The value of the decimal value of the element of the shear shift vectors depends on both the length of the code combination $\mathrm{N}$ and the number of unit symbols $\mathrm{m}$ and zero symbols $\mathrm{N}-\mathrm{m}$ in the code combination of the ring code. The number of decimal values in the vector of the shear indicators is always one less than the number of elements in the code combination, and the number of code combinations of the ring code.

\subsection{Analysis of the structure of vectors of a shear shift of ring codes of family type 000111}

Table 2 shows the dynamics of the structure of the vectors of the shear shift depending on the length of the code combination $N$ with a constant number of units $\mathrm{m}$ in the code combination of ring codes of the family 000111 . Thus in 2 columns of Table 2 the first line of the forming matrix of a ring code is given.

Table 2. Dynamics of changes in the structure of the vector of the shear shift of the ring code type 000111 depending on the length of the code combination $N$ at $\mathrm{m}=3$

\begin{tabular}{|c|c|l|}
\hline $\begin{array}{c}\text { Length of the code } \\
\text { combination N }\end{array}$ & $\begin{array}{c}\text { Structure of the code } \\
\text { combination }\end{array}$ & $\begin{array}{c}\text { Structure of the shear } \\
\text { vector shift }\end{array}$ \\
\hline 7 & 0000111 & 246642 \\
\hline 8 & 00000111 & 2466642 \\
\hline 9 & 000000111 & 24666642 \\
\hline 10 & 0000000111 & 246666642 \\
\hline 11 & 00000000111 & 2466666642 \\
\hline 12 & 000000000111 & 2466666642 \\
\hline
\end{tabular}


Table 3 shows the dynamics of changes in the structure of the vectors of the shear shift depending on the number of units $\mathrm{m}$ in the code combination with a constant length of the code combination $\mathrm{N}$ ring codes.

Table 3. Dynamics of changes in the structure of the vector of the shear shift of the ring code type 000111 depending on the number of units $m$ at $N=8$

\begin{tabular}{|c|c|c|}
\hline $\begin{array}{c}\text { Number of } \\
\text { units of } \mathrm{m}\end{array}$ & $\begin{array}{c}\text { Structure of the code } \\
\text { combination }\end{array}$ & $\begin{array}{c}\text { Structure of the shear } \\
\text { vector shift }\end{array}$ \\
\hline 1 & 00000001 & 2222222 \\
\hline 2 & 00000011 & 2444442 \\
\hline 3 & 00000111 & 2466642 \\
\hline 4 & 00001111 & 2468642 \\
\hline 5 & 00011111 & 2466642 \\
\hline 6 & 00111111 & 2444442 \\
\hline 7 & 01111111 & 2222222 \\
\hline
\end{tabular}

Figure 1 shows a graph of the values of the decimal values of the elements D of the shear vector shift from the position number of the element in the vector of the shear shift $\mathrm{P}$ for a family of ring code type 000111 length $\mathrm{N}=8$ for a different number of unit symbols $\mathrm{m}$

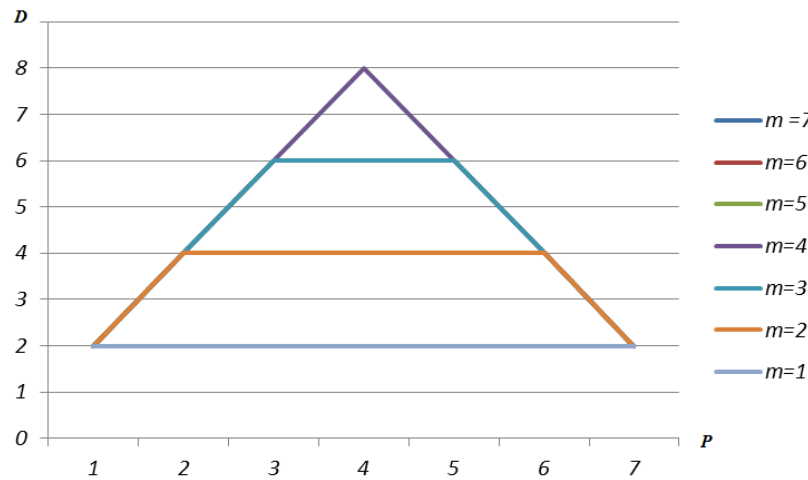

Fig. 1. Graph of the dependence of the value of the decimal values of the elements of the vector of the shear shift on the position number of the element for the code combination of the family 000111

An analysis of the dynamics of the change of the structure of the vectors of the shear shift of the ring code of type 000111, depending on the length of code combination $\mathrm{N}$ and the quantity of units $\mathrm{m}$ given in Tables 2,3 and the dependence of the values of the decimal values of elements $\mathrm{D}$ of the vectors of the shear shift on the number of the position of the placement of the element in the vector of shift $P$, presented in Fig. 1, allows us to note that the numerical series of decimal values of the vector of the shift begins and ends with the number 2 .

Also, the numerical series of decimal values of the vector of shear shift consists of several sets, depending on the number of units in the code sequence and the ratio of the number of units and the number of zeros.

Thus, under the condition $\mathrm{m}=1$ or $\mathrm{N}-\mathrm{m}=1$, a numerical series of length $\mathrm{N}-1=7$ elements is formed, the numerical values of which are equal to $2 \mathrm{~m}$, which means 2 .

If $\mathrm{m}>1$ or $\mathrm{N}-\mathrm{m}>1$, a numerical series is formed, which consists of three sets:

$$
\bar{B} \rightarrow S_{1} \cup S_{2} \cup S_{3}
$$

The decimal values of the elements in the set $S_{1}$ vary in arithmetic progression from 2 to $2 \mathrm{~m}$ and the number of such elements $\mathrm{k} 1$ is equal to:

$$
\mathrm{k}_{1}(\mathrm{~m})=\left\{\begin{array}{l}
2 m, m \leq N-m ; \\
2(N-m), N-m \leq m .
\end{array}\right.
$$

The decimal values of the elements in the set $S_{2}$ do not change and are equal to $2 m$ and the number of such elements $k_{2}$ is equal to:

$$
\mathrm{k}_{2}(\mathrm{~m})=\left\{\begin{array}{l}
\mathrm{N}-\mathrm{m}, \mathrm{m}<\mathrm{N}-\mathrm{m} ; \\
\mathrm{N}-(\mathrm{N}-\mathrm{m}), \mathrm{m}>\mathrm{N}-\mathrm{m} .
\end{array}\right.
$$

The decimal values of the elements in the set $S_{3}$ change into arithmetic progressions from $2 \mathrm{~m}-1$ to 2 .

\subsection{Analysis of the structure of vectors of a shear shift of ring codes of family type 010101}

Table 4 shows the dynamics of the structure of the vectors of the shear shift depending on the length of the code combination $\mathrm{N}$ of the ring codes of the family 010101. Thus, in 2 columns of the table, the first line of the forming matrix of a ring code is given.

Table 4. Dynamics of change of structure of vectors of the shear shift
\begin{tabular}{|c|l|l|}
\hline $\begin{array}{c}\text { Length of code } \\
\text { combination N }\end{array}$ & $\begin{array}{c}\text { Structure of code } \\
\text { combination }\end{array}$ & Structure of shear vector shift \\
\hline 4 & 0101 & 404 \\
\hline 6 & 010101 & 60606 \\
\hline 8 & 01010101 & 8080808 \\
\hline 10 & 0101010101 & 10010010010010 \\
\hline 12 & 010101010101 & 12012012012012012 \\
\hline 14 & 01010101010101 & 14014014014014014014 \\
\hline
\end{tabular}

Table 5 shows the dynamics of the changes in the structure of the vectors of the shear shift depending on the number of units $\mathrm{m}$ in the code combination of the ring codes of the family 010101 .

Table 5. Dynamics of changes in the structure of the vectors of shear shift ring code type 010101 depending on the number of units $m$

\begin{tabular}{|c|l|l|}
\hline $\begin{array}{c}\text { Number of } \\
\text { units } \mathrm{m}\end{array}$ & $\begin{array}{c}\text { Structure of code } \\
\text { combination }\end{array}$ & Structure of shear vector shift \\
\hline 2 & 0101 & 404 \\
\hline 3 & 010101 & 60606 \\
\hline 4 & 01010101 & 8080808 \\
\hline 5 & 0101010101 & 10010010010010 \\
\hline 6 & 010101010101 & 12012012012012012 \\
\hline 7 & 01010101010101 & 14014014014014014014 \\
\hline
\end{tabular}

Figure 1 shows a graph of the values of the decimal values of elements $\mathrm{D}$ of the shear vector shift from the position number of the element in the vector of shear shift $\mathrm{P}$ for the family of ring code type 010101 for a different number of unit symbols $\mathrm{m}$.

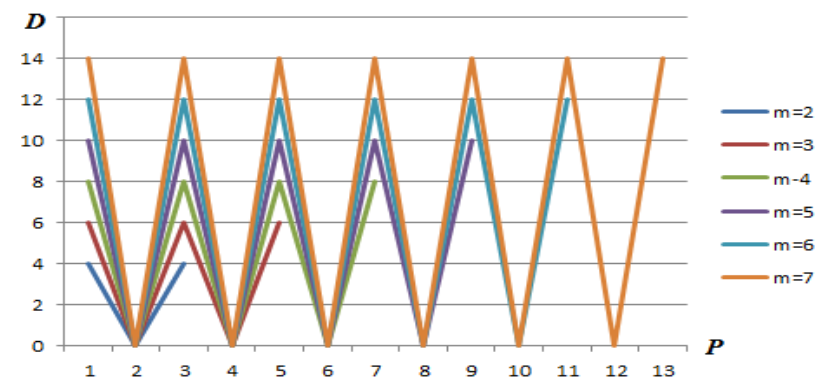

Fig. 2. Graph of the dependence of the value of the decimal values of the elements of the vector of the shear shift on the position number of the element for the code combination of the family 010101

The analysis of the dynamics of changes in the structure of the shear vector shift of the ring code type 010101, depending on the length of the code combination $\mathrm{N}$ and the number of units $\mathrm{m}$ shown in Table 4 and 5 and the dependence of the decimal values of the elements $D$ of the shear vector shift on the position number of the element in the shear vector shift $\mathrm{P}$, presented in Figure 2, allows us to note that the numerical series of decimal values of the vector of the shear shift begins and ends with a number equal to $\mathrm{N}=2 \mathrm{~m}$.

In this case, as can be seen from Table 4 and 5, the family of ring code type 010101 is characterized by code combinations with an even number of elements and when changing both the length $\mathrm{N}$ of the code combination and the number of units $\mathrm{m}$ in the code combination, the structure and dynamics of changing the structure of the vectors of the shear shift are the same. Therefore, there is an unambiguous dependence of the structure of the vectors of the shear shift on both the length $\mathrm{N}$ of the code combination and the number of units $m$ in each code combination. The structure of the vectors of the shear shift is not repeated when changing the number of units in the code combination, which allows us to uniquely determine the code combination on the vector of the shear shift. 
The number of elements $\mathrm{k} 3$ of the vector of the share shift of the ring code family type 010101 is equal to:

$$
\mathrm{k}_{3}(\mathrm{~m})=\left\{\begin{array}{c}
m, x_{k}=2 m ; \\
m-1, x_{k}=0,
\end{array}\right.
$$

where: $x_{k}-$ decimal value of the element vector of the shear shift.

\subsection{Analysis of the structure of vectors of a shear shift of ring codes of family type 001101}

Table 6 shows the dynamics of the structure of the vectors of the shear shift depending on the length of the code combination with a constant number of units $\mathrm{m}$ in the code combination of the ring codes of the family 001101. Thus in 2 columns of the table, the first line of the forming matrix of a ring code is given.

Table 6. Dynamics of changes in the structure of the vector of the shear shift of the ring code type 001101 depending on the length of the code combination $\mathrm{N}$ at $\mathrm{m}=3$

\begin{tabular}{|c|l|l|}
\hline $\begin{array}{c}\text { Length of code } \\
\text { combination N }\end{array}$ & $\begin{array}{c}\text { Structure of code } \\
\text { combination }\end{array}$ & $\begin{array}{c}\text { Structure of vector of } \\
\text { shear shift }\end{array}$ \\
\hline 5 & 01101 & 4224 \\
\hline 6 & 001101 & 44244 \\
\hline 7 & 0001101 & 444444 \\
\hline 8 & 00001101 & 4446444 \\
\hline 9 & 000001101 & 44466444 \\
\hline 10 & 0000001101 & 444666444 \\
\hline 11 & 00000001101 & 4446666444 \\
\hline 12 & 000000001101 & 44466666444 \\
\hline
\end{tabular}

Table 7 shows the dynamics of changes in the structure of the vectors of the shear shift depending on the number of units $\mathrm{m}$ in the code combination with a constant length of the code combination of $\mathrm{N}$ ring codes.

Table 7. Dynamics of changes in the structure of the vectors of the shear shift of ring code type 001101 depending on the number of units $m$ at $N=9$

\begin{tabular}{|c|c|c|}
\hline $\begin{array}{c}\text { Number of } \\
\text { units } \mathrm{m}\end{array}$ & $\begin{array}{c}\text { Structure of code } \\
\text { combinations }\end{array}$ & $\begin{array}{c}\text { Structure of the vector } \\
\text { of shear shift }\end{array}$ \\
\hline 2 & 000000101 & 42444424 \\
\hline 3 & 000001101 & 44466444 \\
\hline 4 & 000011101 & 44666644 \\
\hline 5 & 000111101 & 44666644 \\
\hline 6 & 001111101 & 44466444 \\
\hline 7 & 011111101 & 42444424 \\
\hline
\end{tabular}

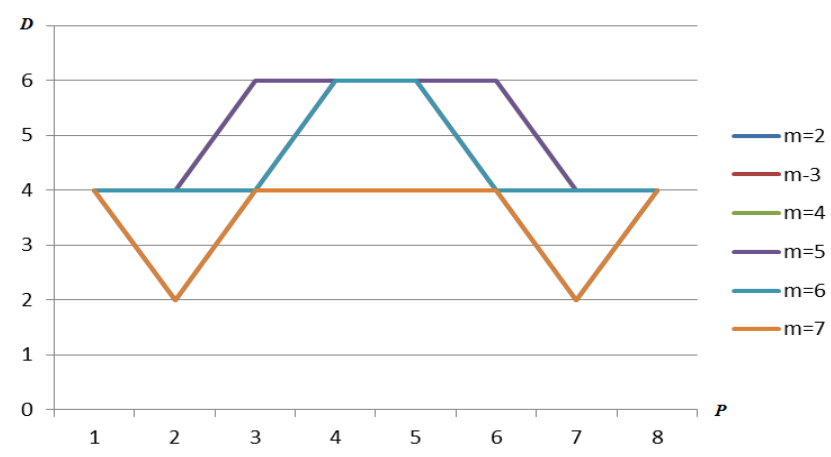

Fig. 3. Graph of the value of the decimal values of the elements of the vector of the shear shift from the position number of the element for the code combination of the family 001101

An analysis of the dynamics of changes in the structure of the VPZ ring code type 001101, depending on the length of the code combination $\mathrm{N}$ and the number of units $\mathrm{m}$ shown in Tables 6 and 7 and the dependence of the values of the decimal values of the elements of $\mathrm{D}$ vector of the shear shift from the position number of the elements presented in Fig. 3, shows that the numerical series of decimal values of the vector of the shear shift begins and ends with the number 4 . The maximum decimal value of the element of the vector of the shear shift is equal to $2 \mathrm{~m}$, meaning equal to 6 . However, the unambiguous dependence of the structure of the vectors of the shear shift on the number of unit symbols $\mathrm{m}$ is not observed. In addition, the structure of the vectors of the shear shift is repeated when changing the number of units in the code combination, which does not allow the code combination to be unambiguously determined by the vector of the shear shift.

\section{Conclusions}

The analysis of the dependence of the structure of the vector shear shift on the properties of ring codes allows us to note that different families of ring codes correspond to different structures of the vector shear shift. Within each family of ring codes, the identity of the values of the decimal values of the elements of the vectors of the shear shift, their combinations and dynamics of their change, is observed. The dependence of the values of the decimal values of the elements on the length $\mathrm{N}$ of the code combinations, the number of unit elements $m$ and the ratio of ones and zeros in the code combination is observed.

The most pronounced abovementioned dependence is observed for the family of type 010101, and the least pronounced dependence is observed for the family of type 001101 .

\section{References}

[1] Berkman L., Otrokh S., Kuzminykh V., Hryshchenko O.: Method of formation shift indexes vector by minimization of polynomials. CEUR Workshop Proceedings 2577, 2019, 259-269.

[2] Gavrilko E. V., Otrokh S. I., Yarosh V. A., Grishchenko L. N.: Improving the quality of the functioning of the network of the future through the use of ring codes. Vesnik svyazi 2/2018, 60-64.

[3] Otrokh S., Kuzminykh V., Hryshchenko O.: Method of forming the ring codes. CEUR Workshop Proceedings 2318, 2018, 188-198.

\section{Ph.D. Vladislav Kravchenk \\ e-mail: vladkr58@gmail.com}

Head of the Department of Mobile and Video Information Technologies of the State University of Telecommunications, Kiev, Ukraine. Research interests: LTE, OFDM, information security.

Publications: about 35 scientific publications, including 3 patents.

http://orcid.org/0000-0002-4758-7027

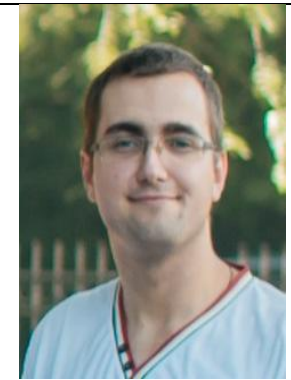

\section{M.Sc. Olena Hryshchenk}

e-mail: elena.grischenko1@gmail.com

Graduate student of the State University of Telecommunications, Kiev, Ukraine. Research interests: information security, information coding. Publications: about 8 scientific publications.

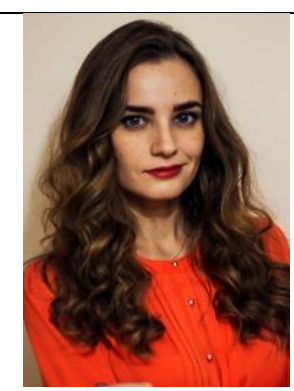

http://orcid.org/0000-0001-8198-5056

\section{MSc. Viktoriia Skrypnik}

e-mail: skripnik2008@ukr.net

Graduate student of the State University of Telecommunications, Kiev, Ukraine. Research interests: information security, information coding. Publications: about 6 scientific publications

http://orcid.org/0000-0001-9854-8039

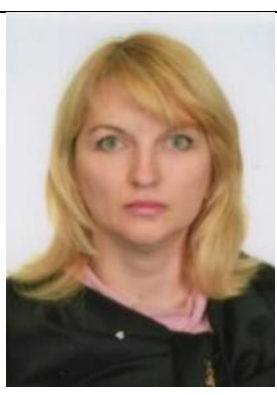

M.Sc. Hanna Dudarieva

e-mail: annett.13.86@gmail.com

Graduate student of the State University of Telecommunications, Kiev, Ukraine. Research interests: information security, information coding. Publications: about 7 scientific publications.

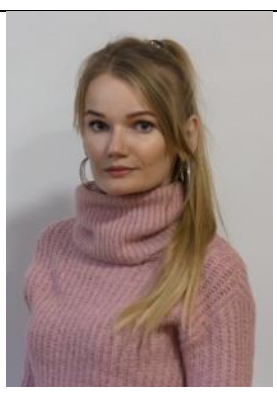

